\title{
Digitalization of environmental education is the trend of its modernization and reform
}

\author{
Kirill Grevtsov ${ }^{1,}{ }^{*}$, Oksana Kadeeva $^{1}$, Valentina Syritsyna ${ }^{1}$, Oleg Ilchenko ${ }^{1}$, and Alexander \\ Belov $^{1,2}$ \\ ${ }^{1}$ Far Eastern Federal University, 10, Ajax village, 690922, Primorsky Krai, Vladivostok, Russian \\ Island, Russia, \\ ${ }^{2}$ Primorsky State Agricultural Academy, 44, Blucher Ave., 692510, Ussuriysk, Primorsky Krai, \\ Russia
}

\begin{abstract}
Over time, the education system around the world has undergone dramatic changes. The traditional education system no longer meets today's complex needs, where everything is dynamic and evolving at a very rapid pace. In today's world, a huge number of transformations take place in every nanosecond. Therefore, a new, modern way of learning is needed to systematically cope with such transformations arising from the creation of vast amounts of information. Thus, to address the shortcomings of the traditional education system, the world is moving towards digital education, which solves all the problems and challenges of traditional education. The authors present a comprehensive analysis of the processes of digitalization of education, most actively proceeding in the modern world. The formation of the knowledge society and the digital stage of modern civilizational culture is still a continuous process, which itself is experiencing serious internal contradictions and problems, especially in our country. One of the serious obstacles to the modernization of education is the mismatch between the speed of educational resources and the rate at which the digitalization of the educational process itself is taking place, which is still very low. Education reform is presented in the article by the example of various forms of educational and extracurricular activities aimed at the active use of digital educational resources, including the citywide electronic journal and diary, which has been used for several years in many schools in Russia.
\end{abstract}

\section{Introduction}

Digitalization of education is a powerful trend in reforming and modernizing the global educational environment [1,2]. Digitalization means the transformation of all kinds of information (texts, sounds, videos, and other data from various sources) into a digital language. Discussing the phenomenon of digitalization, it should be noted that various analysts and experts (mostly British, including Tim Berners-Lee - one of the inventors of the World Wide Web [3]) consider the transition of the educational process to the digital stage as a turning point in the history of education. It is assumed that the UK will be the first in the world to introduce compulsory software and IT education into the curriculum for

\footnotetext{
* Corresponding author: kirillgrevcov@gmail.com
} 
schoolchildren aged 5 to 16 . The stated approach has been adopted by the European Union. The EU Education Strategy 2020, adopted in 2014, focuses on digital technologies [4]. This document proved to be an impressive achievement in the field of information technology, the main goal of which was to integrate modern solutions into the activities of educational institutions across the EU.

\section{Research methods and principles}

This strategy is part of a comprehensive strategic concept of digital education called "Touchthefuture", developed based on the EU government document "DigEduPol" [5]. The main goal is to integrate digital technologies into the educational process so that they go hand in hand with the teaching of individual subjects, as well as with the school educational process as a whole. Thus, the technologies of the XXI century should not only help students to learn certain facts but also increase their competence, develop logical thinking and communication skills.

Distance education based on the new possibilities of digital technology is a separate issue within the trend of digitalization of education $[6,7,8,9]$. One of the main advantages of digital technology integration in the educational process is that the teacher can control the practical effectiveness of the learning process, the quality of learning material, the time spent by the student to solve this or that problem, the level of understanding of new information, etc., while traditional methods of control provide a "rough" assessment of progress (for example, based on final grades). Digital technologies help teachers to reduce paperwork: notebooks and reports are placed on laptops or tablets where all necessary academic information is available. Students' homework assignments, except when special teacher guidance is required, can be automatically monitored by software tools. Students also receive obvious benefits. Today's digital technology allows them to work on any task as a group, share opinions and ideas with classmates and the teacher, design their life path and achieve better results in a shorter amount of time. Devices such as interactive tablets for presentations, seminars, and conferences allow you to "catch the eye" of a wider audience, just as 3D modeling technology allows you to visualize any idea-graphic presentation in 2D-plane, helping to solve problems creatively and informally. According to scientists, very soon the digital format will eliminate the need for handwritten lectures when each student will receive all materials and will be able to process them in real-time and work interactively. All texts will be available online and stored in a digital "cloud" (an alternative to AppleiCloud, YandexDisk), which will virtually eliminate any negative consequences associated with absence from school.

\section{Main results}

The intensive penetration of digital technology in education raises several practical questions.

As with other innovations, the world of online technology is associated with certain contradictions and contingencies. For example, parents who want their child to spend less time at the computer must change their minds, since the modernization of the educational process suggests otherwise. LegoGroup tried to solve this problem in 2014 and published the results of its research in The Guardian magazine. According to Lego analysts, "Every educational situation and every child is unique, so parents need to determine how much time their child can spend in front of the computer. Therefore, it is very important to interactively find a solution regarding the correct "digital" behavior of the student and develop "rules for digital activities" [10]. Although this statement applies directly to video games, it can be applied to any "digital" activity, especially, as mentioned above, we are faced with the need 
to combine games and education, especially in elementary schools. Durham University has completed research on the impact of digital technology on education and made some interesting findings. According to its experts, digital technologies should only complement but not supplant traditional teaching methods, and their full potential should be used by students with disabilities or special needs. The best results can be achieved by using them at intervals of about three times a week since frequent use of innovative and primarily digital methods can gradually reduce the efficiency of students' information processing. Finally, scholars emphasize the importance of professional development workshops for teachers who will use digital technologies in their work [11]. Another problem in this context is the comprehensive digitalization of human life, predicted by numerous scholars [12]. Today, digital technology is in a state of intensive development and will soon reach the oil industry in terms of turnover. At the same time, the demands of society begin to grow, forcing us to adapt to the progress of the $21 \mathrm{st}$ century. The ability to adapt to new technology is now a prerequisite for success, as stated in Newsletter 8 of Heys, a global recruiting company. "The digital revolution has affected every aspect of life around the world," says Ladislav Kucera, the company's chief analyst. And CEOs, CFOs, sales, and marketing professionals are using new digital technologies more frequently in their work. The growing number of online transactions is encouraging business people to process data online. Teams are evaluating companies and contacting customers electronically, attaching news and accompanying offers to their messages. Such tasks involve a deeper knowledge of digital technology than the average user. According to Haysrecruiting, employers are increasingly demanding HTML and SQL knowledge from senior employees. Other business technologies have recently been expanded by a wide range of new digital solutions. The aforementioned phenomena are causing the general education system to react to students' mastery of the digital realm and tools at a young age. Kucera states, "Be prepared for the fact that after a while, most jobs will require knowledge of the latest technologies, which are constantly expanding and progressing. Regardless of the profession or industry that now encompasses the bulk of human resources, companies and organizations want to hire and retain personnel who know these technologies and are willing to upgrade their skills" [13]. Another important trend in the development of education in the context of globalization is institutional organization. The Khan Academy is now a multidisciplinary global institution with several leaders and more than 80 faculty members actively engaged in its activities with a wide range of activities [14]: from online lectures and seminars for academy students to an extensive archive of special digital records used as a huge digital library. A key feature of the Academy is a simplified form of participation and attendance (in-person, remotely online, or offline). This academy concept was created when Sal Khan was working as a hedge fund analyst in California, and in between doing online training for people from all over the country. At some point, he had collected enough entries, and his colleagues at Google advised him to upload those entries to a YouTube channel. Soon after, Han received feedback from people all over the country and abroad, especially in Singapore. The channel turned out to be the starting point for today's Khan Academy. The Academy is a non-profit organization offering a new approach to education based on principles that (according to S. Khan) best reflect the coming stage of educational development [15]:

1. Information should be free of charge.

2. It is necessary to use as much new technology as possible.

3. Individual approach to every student.

4. Comfortable and pleasant educational process.

The Academy provides direct and immediate access to teaching aids and classes according to the following algorithm: "in your own time and at your own pace, with the opportunity to stop and repeat." S. Hahn tried to understand how videotaping could replace the classroom teacher, especially in humanities subjects such as history and literature, which 
he was interested in under the influence of Umberto Eco. A course on the history of the French Revolution was an attempt of sorts, as a way was found to go beyond the "talking head." The notes emphasized not so much the fact itself (though not ignored) as an analysis of the meaning of the Revolution in a broad historical context and a simple explanation of why the Revolution changed the world. Today, Khan Academy is a large organization whose a base of over 400 million students in 28 languages.

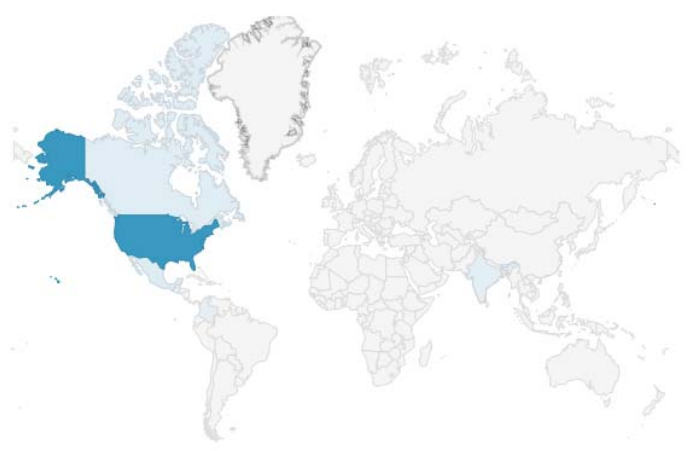

\begin{tabular}{|c|c|c|}
\hline United States & $57.22 \%$ & $\wedge 3.93 \%$ \\
\hline [-1 Mexico & $4.56 \%$ & A21.38\% \\
\hline 【४\| Canada & $3.70 \%$ & A $1.46 \%$ \\
\hline India & $2.73 \%$ & $\sim 9.30 \%$ \\
\hline - Colombia & $2.33 \%$ & $\wedge 115.7 \%$ \\
\hline \multicolumn{3}{|c|}{ See 247 more countries } \\
\hline
\end{tabular}

Fig. 1. Language coverage of the resource.

The academy's average monthly enrollment is about 2 million students. people studying mathematics, biology, history, computer science, and other subjects.

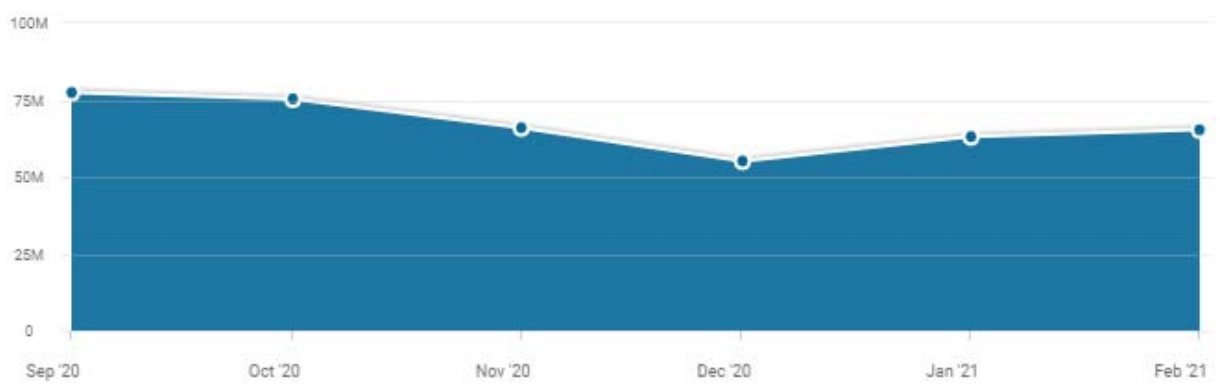

Fig. 2. Average resource traffic.

The Academy's YouTube channel currently has 6,500 free video lessons, which are the core of the learning platform with access provided for free and without registration. Additional lessons and courses are available after registration on the academy website. The gaming element is heavily involved in the academy with special badges appearing after completing any of the 20 levels. In any case, according to analysts, today Khan Academy is the full embodiment of the principle of education of the future "Learn what you want, how you want!" At present, the digitalization of education in the Russian Federation is closely connected with the implementation of federal state educational standards (FSES), developed for all levels of education. For example, the essence of the FSES of basic general education is "the formation and development of basic competencies in the use of information and communication technologies; motivating students to actively use dictionaries and other search engines", including these elements in the meta-disciplinary results of mastering the basic educational program in the conditions of basic general education. One of the tools to achieve the stated goals is "access to school library and Internet information resources, textbooks and popular literature, media sources on electronic media, copying machines to replicate teaching aids, methodological materials, texts and graphics, audio and video information, creative, research, and development content, as well as student projects" [16]. 
Another important state document promoting the concept of digitalization of education in Russia is the priority project "Modern Digital Educational Environment in the Russian Federation," the main goal of which is to create conditions by 2021 to improve the overall quality and expand continuing education opportunities for all citizens through the development of the Russian digital educational environment and increase the number of online students to 11 million by the end of 2025 [17]. Against the background of the general situation in the world.

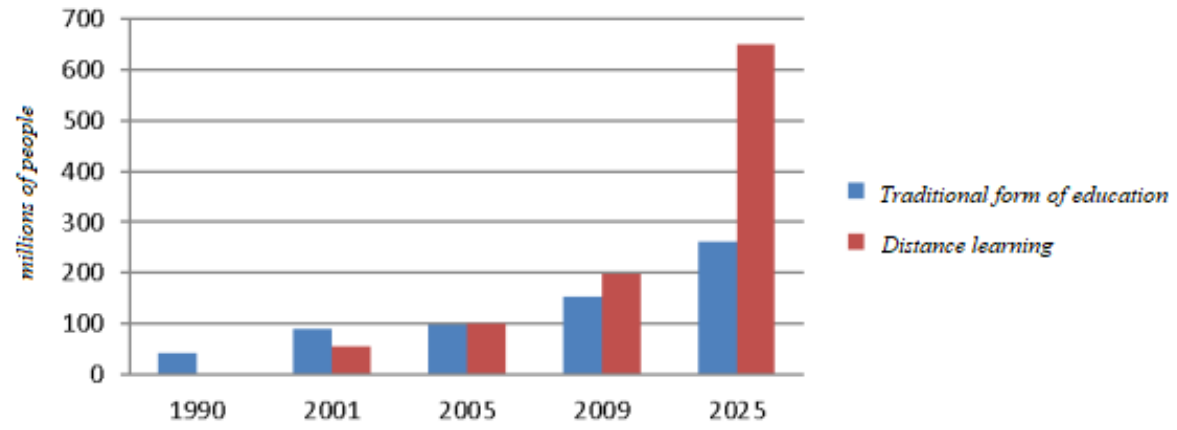

Fig. 3. Estimated number of people studying using distance learning technologies.

At present, leading Russian institutions of higher education are actively involved in their projects of digitalization of education. For example, the authors of the current concept of the boarding school for gifted children at Lomonosov Moscow State University (MSU) believe that intellectual education should go hand in hand with traditional educational models and methods. The school offers video lessons by the best teachers (including foreign ones), online seminars, discussions, and conferences. Leading MSU and foreign scientists will be engaged in master classes and seminars in a distance learning environment [18]. One of the objects of the step-by-step reform and subsequent modernization of Russian education, implemented in a pilot format in general education schools, is a city-wide electronic journal and diary of students, which, for example, allows students to assess their activities, choosing a certain scale most appropriate to the individual characteristics of each student.

\section{Discussion}

However, it should be noted that the declared trend of digitalization of education in Russia soon may cause numerous problems for schools [19]. Firstly, it is the digital gap between the provision of information gadgets to students who actively use them and traditional approaches to learning. Therefore, digitalization has both loyal followers and skeptical opponents. Thus, there are opinions that the new solutions will personalize the educational process, adapting the program to the individual needs of the student. If technology enhances comprehension, memorization, knowledge, or the use of any content, it is worth considering and adopting, even if it involves fundamental changes in learning activities. However, there are also skeptical views that argue that the digitalization of Russian education poses serious challenges, so the digitalization of educational resources (e.g., textbooks) does not keep up with the informatization of the educational process. Education lacks initiatives related to the intensification of the communicative component of education using information technology, as well as basic ideas. This sphere requires a constant flow of breakthrough ideas and venture projects [20]. The above-mentioned innovative trends will determine the development of education in the context of globalization and, as mentioned above, will influence all aspects of education and be accompanied by serious changes in the learning activities, i.e. classroom work. The classroom of the future will not be a typical picture - teachers in front of their 
students sitting at desks arranged in perfect rows. The introduction of innovative digital technologies will change not only the form and tools of learning but its environment as such.

\section{Conclusion}

It can be stated that the modern education system is experiencing a creative crisis. Classroom work and lessons do not contribute to the personal initiative of students to learn something new, to make an objective connection between their knowledge and the real world, to use their imagination to find non-standard answers to standard questions instead of using stereotypical models. Therefore, the classroom of the future should not be a place for transmitting knowledge, but rather a place for investing in students' minds, focusing on creativity and innovation, rather than repeating ready-made opinions or mechanically answering test questions. The stated approach to education will force us to rethink curricula and integrate conceptual and current innovations. The new curricula should not only provide for the mandatory transfer of facts, but also focus on student achievement, namely creativity, imagination, and teamwork, regardless of the location of team members. Finally, it should be noted that contemporary Global Education has faced a major transformation brought about by the continued integration of new digital technologies into learning activities, and is actively seeking effective implementation models that will compromise tradition and innovation.

\section{References}

1. The concept of creation and development of the information and educational environment of Open Education of the education system of the Russian Federation, http://do.sgu.ru/conc.html

2. A.A. Strokov, Digitalization Of Education: Problems And Prospects, https://cyberleninka.ru/article/n/tsifrovizatsiya-obrazovaniya-problemy-iperspektivy/viewer/

3. N. Pearce, M. Weller, E. Scanlon, S. Kinsley, Durh. res. onl. 16(1), $72-80$ (2011)

4. Europe 2020-Europes growth strategy, http://ec.europa.eu/europe2020/

5. Digital Dawn. Hays recruiting revue 8(46), 18-26 (2015)

6. S.B. Pashkin, N.B. Lisovskaya, Collection: Professional education, science and innovation in the XXI century proceedings of the XII St. Petersburg Congress, 189-191 (2018)

7. E.N. Klochkova, N.A. Sadovnikova, Open education 23(4), 13-22 (2019) https://doi.org/10.21686/1818 - 4243-2019-4-13-22

8. M. Popova, RBC + Education 050(2306), 1-2 (2016)

9. V.V. Eremin, E.V. Kharisova, MSU boarding school for gifted children is a model of learning in a changing world. Natural science education: a look into the future. Collection (MSU Publishing, Moscow, 2016)

10. K. Stuart, What every parent needs to know about video games: a crash course (2014) https:/www.theguardian.com/technology/2014/jun/02/parents-guide-videogamesplaystation-xbox-wii-apps-children

11. V.I. Kolykhmatov, Interregional scientific and practical conference "Pedagogical search: innovative experience, problems of quality of professional development of a teacher": collection of materials (St. Petersburg, 2019) 
12. V.G. Khalin, G.V. Chernova, Digitalization and its impact on the Russian economy and society: advantages, challenges, threats and risks, https://spb.ranepa.ru/images/nauka/UK_DOI/10_18/Khalin_10_18.pdf

13. Hays recruiting revue 8(46), 3 (2015)

14. Khan academy, https://ru.khanacademy.org/about

15. Khan principles, https://www.khanacademy.org

16. Order of the ministry of education of the russian federation no. 649 of december 2 (2019) https://www.garant.ru/products/ipo/prime/doc/73235976/

17. Project Modern digital educational environment in the Russian Federation, http://neorusedu.ru

18. V.A. Sadovnichy, Summer School of Moscow State University Yu. P. Zinchenko, http://rusacademedu.ru/news/rao-i-mgu-provodyat-letnyuyu-shkolu-dlya-uchitelej/

19. B.E. Starichenko, Digitalization Of Education: Realities And Problems, http://journals.uspu.ru/attachments/article/2610/2.pdf

20. E. Tuzhikova, Information And Communication Technologies In Modern Education, https://cyberleninka.ru/article/n/informatsionno-kommunikativnye-tehnologii-vsovremennom-obrazovanii/viewer 